\title{
CARACTERIZAÇÃO FOTOSSINTÉTICA DA ESPÉCIE ISOHÍDRICA PATA-DE-ELEFANTE EM CONDIÇÕES DE DEFICIÊNCIA HÍDRICA ${ }^{1}$
}

\author{
SUZANA CHIARI BERTOLLI ${ }^{2,3^{*}}$, JULIANO DE SOUZA ${ }^{3}$, GUSTAVO MAIA SOUZA ${ }^{3}$
}

\begin{abstract}
RESUMO - A manutenção do status hídrico de uma planta é essencial para seu desenvolvimento adequado em ambientes com limitação da disponibilidade de água. Diferentes espécies possuem diversos mecanismos que conferem maior habilidade de sobrevivência em condições de seca. O objetivo deste estudo foi avaliar as alterações de parâmetros fisiológicos da espécie isohídrica Beaucarnea recurvata Lem. O estudo envolveu experimentos com desidratação lenta (DL) realizado por meio da suspensão da irrigação seguida por reidratação, e com desidratação rápida (DR), onde folhas individuais foram destacadas e colocadas para desidratar em bancada de laboratório. Os resultados mostraram que apesar da porcentagem de água no solo atingir valores críticos $(12 \%)$ logo nos primeiros dias de DL as plantas apresentaram manutenção do conteúdo relativo de água $(\cong 80 \%)$ ao longo de 54 dias de DL, quando a fotossíntese líquida $\left(P_{N}\right)$ atingiu valores nulos. Ao longo de DL foi observado que a $P_{N}$, a condutância estomática (gs), a eficiência instantânea de carboxilação, a eficiência fotoquímica e o conteúdo de clorofila foram reduzidos. No experimento de DR foi observada alta correlação entre $P_{N} e g s$. Os resultados sugerem que a redução da fotossíntese foi inicialmente causada por um ajuste estomático, culminando com um desequilíbrio entre a produção de energia fotoquímica e o seu consumo pelo aparato bioquímico da fotossíntese. Entretanto, após a reidratação, os parâmetros de trocas gasosas foram recuperados, indicando que o comportamento isohídrico dessa espécie contribuiu para que as plantas não sofressem danos extensivos durante um período prolongado de suspensão da irrigação.
\end{abstract}

Palavras-chave: Beaucarnea recurvata Lem. Desidratação. Regulação hídrica. Trocas gasosas.

\section{PHOTOSYNTHETIC CHARACTERIZATION OF THE ISOHIDRIC SPECIES PONYTAIL PALM UNDER WATER DEFICIT}

\begin{abstract}
The maintenance of a plant water status is essential for keeping of its development in environments with limited water availability. Different species have different mechanisms that provide greater ability to survive under drought conditions. The objective of this study was to evaluate physiological parameters changes of the isohydric species Beaucarnea recurvate Lem. under irrigation suspension. The study involved experiments with slow dehydration (SD) performed by withholding water followed by plants rehydration, and with rapid dehydration (RD), where individual leaves were detached and placed to dehydrate in the laboratory bench. The results showed that although of the soil water content $\left(\% \mathrm{H}_{2} \mathrm{O}\right)$ reach critical values $(12 \%)$ in the first days of the irrigation suspension, the plants showed maintenance of the relative water content $(\cong 80 \%)$ over the 54-day SD period, when the net photosynthesis $\left(P_{N}\right)$ reached null values. Throughout SD, it was observed that the $P_{N}$, stomatal conductance $\left(g_{s}\right)$, instantaneous carboxylation efficiency, the electrons transport rate, the potential quantum efficiency of PSII and chlorophyll content were reduced. In RD, experiment was observed a high correlation between $P_{N}$ and $g_{s}$. The results suggest that the reduction in photosynthesis was initially caused by a stomatal adjustment that culminated in an imbalance between photochemical energy production and its consumption by biochemical apparatus of photosynthesis. However, after rehydration, all gas exchange parameters were recovered, indicating that the isohydric behavior of this species contributed to the plants did not suffer extensive damage during a prolonged period of irrigation suspension.
\end{abstract}

Keywords: Beaucarnea recurvata Lem.. Dehydration. Gas exchange.Water regulation.

\footnotetext{
*Autor para correspondência

${ }^{1}$ Recebido para publicação em 22/04/2014; aceito em 07/04/2015.

${ }^{2}$ Programa de Pós-Graduação em Biologia Vegetal, Departamento de Botânica, Instituto de Biociências, Universidade Estadual Paulista "Júlio de Mesquita Filho" (UNESP), Rio Claro (SP), Brasil; scbertolli@hotmail.com.

${ }^{3}$ Laboratório de Inteligência em Plantas e Ecofisiologia "Ulrich Lüttge", Universidade do Oeste Paulista (UNOESTE), Presidente Prudente (SP), Brasil; juliano_dulao@hotmail.com,gumaia.gms@gmail.com.
} 


\section{INTRODUÇÃO}

Em situações de restrição de água no solo e/ ou em condições de alta demanda atmosférica as plantas apresentam diferentes mecanismos para a manutenção de sua homeostase hídrica, sobretudo por meio da regulação da abertura dos poros estomáticos, reduzindo a transpiração (BUCKLEY, 2005). Além do controle estomático, algumas espécies possuem atributos morfológicos que contribuem para a manutenção do status hídrico como, por exemplo, a suculência em plantas, definida como a presença de tecidos espessados em seus órgãos com a função primária de armazenar água, podendo evitar ou minimizar o estresse hídrico (GIBSON, 1982; VON WILLERT, 1992). O transporte de água dos tecidos de armazenamento para tecidos fotossintéticos e a força que dirige tal distribuição (gradiente de potencial de água) dá suporte para a sobrevivência de plantas durante um período de deficiência hídrica (BOBICH; NORTH, 2009).

A manutenção do status hídrico das plantas, apesar do decréscimo da umidade do solo e da atmosfera, é denominado como comportamento isohídrico (MASEDA; FERNÁNDEZ, 2006; MCDOWELL, et al. 2008). Por outro lado, espécies de plantas anisohídricas apresentam uma redução expressiva do potencial de água durante um período de deficiência hídrica sem o comprometimento de outras funções (POU et al., 2012). Em espécies isohídricas, além de órgãos de armazenamento de água outros mecanismos contribuem com a manutenção do potencial de água, tais como a variação da condutância estomática, as mudanças nos padrões de absorção de água, as variações na arquitetura hidráulica e as mudanças na superfície total de trocas gasosas (BUCCI et al., 2008). Contudo, o desempenho de plantas com diferentes modos de regulação hídrica depende da intensidade e da duração da escassez de água (MCDOWELL et al., 2008). Por exemplo, em condições de seca, espécies isohídricas fecham os estômatos, a fim de manter o potencial de água na folha constante. No entanto, se o período de escassez de água é muito longo as plantas podem sofrer deficiência de carbono.

Em situação de deficiência hídrica normalmente é observado uma baixa regulação da fotossíntese. A redução da eficiência fotossintética é detectada quando existe um desequilíbrio entre a energia capturada pelos fotossistemas e a energia convertida bioquimicamente (KRAMER; EVANS, 2011; BERTOLLI et al., 2012), provocando limitações estomáticas e não-estomáticas. O fechamento dos poros estomáticos é reconhecido como uma das primeiras respostas das plantas em condições de deficiência hídrica, reduzindo a perda de água por transpiração e, ao mesmo tempo, diminuindo o fluxo de entrada de $\mathrm{CO}_{2}$ até a cavidade subestomática. Esta resposta frequentemente reduz a concentração de $\mathrm{CO}_{2}$ nos cloroplastos disponível para o sítio ativo de carboxi- lação da enzima Rubisco (CHAVES et al., 2009; PINHEIRO; CHAVES, 2011). A redução da assimilação de carbono ainda pode ser atribuída a problemas no aparato fotoquímico, em função de uma redução no transporte de elétrons e diminuição na síntese de ATP e NADP(H) (FLEXAS et al., 2006). Além disso, o decréscimo da fotossíntese pode ocorrer devido a uma limitação bioquímica, como a redução da eficiência enzimática do ciclo de Calvin, incluindo a limitação da regeneração da RuBP (LAWLOR; TEZARA, 2009; PINHEIRO; CHAVES, 2011).

Beaucarnea recurvata Lem. é uma espécie monocotiledônea, de metabolismo fotossintético C3, pertencente à família Ruscaceae e considerada uma espécie semi-lenhosa arbustiva originária do México (LORENZI; SOUZA, 2008). Segundo Bobich e North (2009), B. recurvata é uma espécie suculenta do tipo paquicaule, ou seja, possui tronco espessado em comparação ao resto do seu corpo, permitindo o armazenamento de uma grande quantidade de água. Dessa forma, pretende-se testar neste estudo a hipótese de que essa característica morfológica deve contribuir com o suprimento de água e, consequentemente, manter a atividade fotossintética apesar das condições ambientais adversas, caracterizando-a como uma espécie de comportamento isohídrico. Apesar do alto valor comercial para o paisagismo, o desempenho fisiológico geral de $B$. recurvata, em relação às perturbações ambientais, ainda não foi estudado.

O objetivo deste estudo foi avaliar as alterações de parâmetros fotossintéticos de plantas de $B$. recurvata que foram submetidas à deficiência hídrica por meio da suspenção de irrigação, contribuindo para um melhor entendimento da fisiologia dessa espécie ornamental cultivada sob condições de restrição de água.

\section{MATERIAIS E MÉTODOS}

O estudo foi conduzido em condições de casa de vegetação climatizada. Para a implantação dos experimentos foram utilizadas mudas de $B$. recurvata obtidas de viveiro comercial no município de Colorado (PR) e cultivadas em vasos de 5 litros, com um ano e seis meses de idade. O estudo envolveu dois experimentos: um de desidratação lenta (DL); e outro de desidratação rápida (DR).

Antes do início dos tratamentos as plantas foram aclimatadas às condições da casa de vegetação e mantidas sob irrigação constante durante 30 dias. $\mathrm{O}$ experimento DL foi realizado baseado em um tratamento de indução de deficiência hídrica por meio da suspensão da irrigação, seguida por reidratação das plantas. Os períodos de suspensão e reidratação foram determinados em função dos valores de trocas gasosas foliares medidos diariamente (conforme descrito mais adiante). No experimento DR, folhas indi- 
viduais de plantas que foram mantidas em condições de irrigação constante foram destacadas e colocadas para desidratar na bancada do laboratório. Ambos os experimentos foram realizados com seis repetições (seis plantas individuais para cada experimento).

Durante o experimento DL foi feito um acompanhamento da porcentagem de água no solo $\left(\% \mathrm{H}_{2} \mathrm{O}\right)$ utilizando sensores de umidade de solo (EC-TM, Decagon Devices, EUA) diariamente no período da manhã. A desidratação das folhas foi monitorada em intervalos de vinte e quatro horas por meio de medidas de conteúdo relativo de água (CRA). O CRA é uma estimativa direta da porcentagem de água na folha e foi calculado, segundo Larcher (2000), como [CRA = (Mf - Ms)/ (Msat Ms) x 100 (\%)]: onde Mf corresponde a massa fresca da folha pesada imediatamente após a coleta; Msat corresponde a massa da folha sob saturação de água, após imersão durante $12 \mathrm{~h}$ em água destilada; e Ms corresponde a massa seca obtida após secagem das folhas em estufa a $60^{\circ} \mathrm{C}$ até obtenção de massa constante.

A fotossíntese das plantas ao longo do experimento DL foi avaliada por meio de análise de fluorescência da clorofila a (análise fotoquímica) e medidas de trocas gasosas foliares. Os parâmetros fotoquímicos foram obtidos a partir de um medidor portátil de luz modulada (modelo FMS-2, Hansatech, UK). As medidas foram realizadas em dias alternados entre às 11:00h e 13:00h, simultaneamente às medidas de CRA. Em cada repetição foi escolhida uma folha totalmente expandida, sem sinais aparentes de doenças ou deficiência nutricional. Os parâmetros determinados foram: eficiência quântica potencial $\left(F_{v} / F_{m}\right)$ e efetiva $\left(\phi P S I I=\Delta \mathrm{F} / \mathrm{F}_{\mathrm{m}}{ }^{\prime}\right)$ do fotossistema II; coeficiente de extinção fotoquímico da fluorescência $\left(q_{P}\right)$; e a taxa de transporte de elétrons $(\mathrm{ETR}=D F F F * \phi P S I I * 0,5 * 0,84)$ (BILGER e BJÖRKMAN, 1990). Os valores de $F_{m}$ e $F_{v}$ indicam, respectivamente, as fluorescências máxima e variável, determinadas após 30 minutos de adaptação ao escuro. $F_{m}$ 'é a fluorescência máxima na presença de luz e $D F F F$ a densidade de fluxo de fótons fotossinteticamente ativo.

As medidas de trocas gasosas, feitas de forma simultânea às medidas de fluorescência da clorofila $a$, foram registradas até que as plantas atingissem valores de fotossíntese líquida próximos a zero. Para este monitoramento, foi utilizado um medidor portátil de trocas gasosas (modelo CIRAS-2, PPSystem, UK). Quando a fotossíntese líquida atingiu valores nulos (após 54 dias de SI) as plantas foram reidratadas e uma nova análise de trocas gasosas e de fluorescência da clorofila $a$ foi realizada após 24 horas, a fim de se determinar a capacidade de recuperação das plantas. As condições da câmara de amostragem foliar do medidor de trocas gasosas foram mantidas a uma temperatura de $30^{\circ} \mathrm{C}$, umidade relativa do ar em $60 \%$, concentração externa de $\mathrm{CO}_{2}$ de $380 \mu \mathrm{mol} \mathrm{mol}^{-1}$ e irradiância saturante de $1200 \mu \mathrm{mol}$ fótons $\mathrm{m}^{-2} \mathrm{~s}^{-1}$. Os parâmetros de trocas gasosas analisados foram: fotossíntese líquida $\left(P_{N}\right)$; condutância estomática $\left(g_{s}\right)$; e concentração intercelular de $\mathrm{CO}_{2}\left(\mathrm{C}_{\mathrm{i}}\right)$. A partir desses dados foi calculada a eficiência instantânea de carboxilação (EIC), calculada como a relação entre $P_{N}$ e $\mathrm{C}_{\mathrm{i}}$.

Também foi avaliado o Índice do Conteúdo de Clorofila (ICC), estimado por um medidor de conteúdo de clorofila (CCM-200 Opti-Sciences, Tyngsborb, Massachusetts, USA) baseado na absorbância em comprimento de onda de 660 e $950 \mathrm{~nm}$. As medidas foram realizadas no início da DL e ao final dos 54 dias de suspensão da irrigação (SI).

No experimento DR foram realizadas medidas de trocas gasosas a cada dez minutos até que a fotossíntese líquida atingisse valores nulos. As condições da câmara de amostragem do medidor de trocas gasosas em que as folhas destacadas eram monitoradas durante a desidratação foram as mesmas do experimento DL.

Os resultados de CRA e $\% \mathrm{H}_{2} \mathrm{O}$ do experimento DL foram analisados por regressão linear em função do tempo ao longo do período de suspensão da irrigação. Os parâmetros de fluorescência da clorofila $a$ foram analisados por meio de correlação linear com o CRA, assim como para os dados de trocas gasosas. Os parâmetros de trocas gasosas e ICC foram avaliadas por meio de ANOVA e comparação de médias por teste de Tukey $(\mathrm{p}=0,05)$. Os resultados de trocas gasosas do experimento DR foram analisados por meio de correlações lineares entre os parâmetros medidos.

\section{RESULTADOS E DISCUSSÃO}

A umidade do solo decaiu rapidamente após a indução de deficiência hídrica como indicado pelos valores de porcentagem de água do solo $\left(\% \mathrm{H}_{2} \mathrm{O}\right)$ (Figura 1), atingindo valores críticos de umidade (aproximadamente 12\%) em apenas 8 dias. Após este período a umidade do solo ficou abaixo do limiar de medida do equipamento, que é abaixo de $10 \%$. Quanto ao conteúdo relativo de água (CRA) foi observada um tendência significativa de redução (aprox. de 95 para 80\%) durante o período de 54 dias de DL, ou seja, no momento em que a fotossíntese líquida chegou a valores nulos. Além disso, foi possível notar que ocorreram oscilações em torno de $5 \%$ nos valores de CRA com uma frequência básica de 5 dias entre vales e picos nos primeiros 15 dias de DL e depois com intervalos de 10 dias até o final do experimento, estabilizando em $80 \%$ de CRA (Figura 1). 


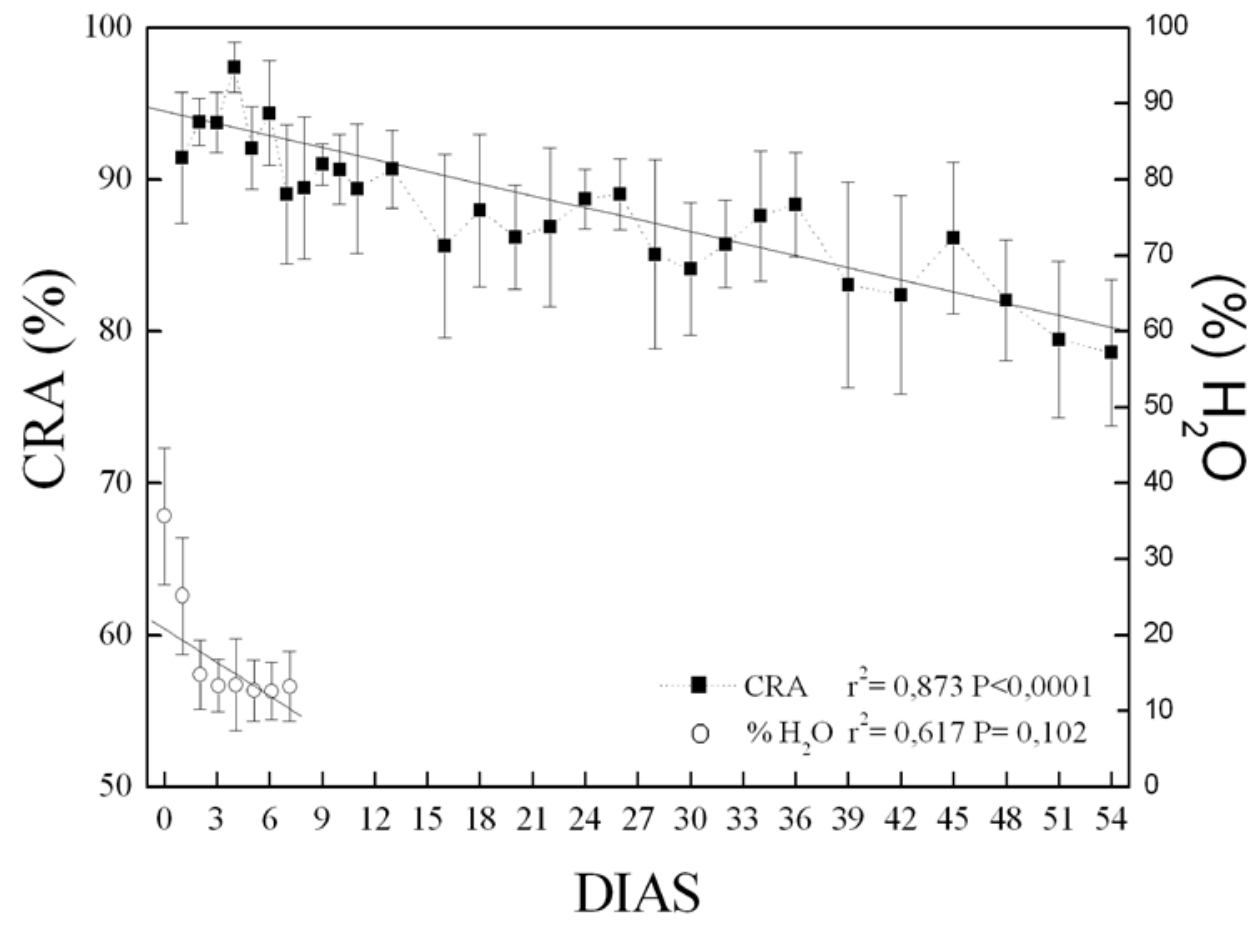

Figura 1. Porcentagem de água no solo $\left(\% \mathrm{H}_{2} \mathrm{O}\right)$ e conteúdo relativo de água (CRA) medidos a cada dia após a suspensão da irrigação na indução de desidratação lenta (DL). As médias foram obtidas a partir de oito repetições.

A variação do CRA de $B$. recurvata mostrouse independente do decréscimo da umidade do solo durante o período de suspensão da irrigação (Figura 1). Essa independência do CRA em relação a água disponível no solo é característico de plantas "paquicaules". Espécies paquicaules apresentam uma grande quantidade de parênquima que armazena água em seus troncos e permite a manutenção da hidratação das folhas apesar das condições ambientais adversas (BOBICH; NORTH, 2009). As oscilações de CRA que foram observadas ao longo do período de DL sugerem que as plantas distribuíram parte da água estocada no tronco espessado para as folhas a medida que o déficit hídrico atingia valores críticos periodicamente, permitindo a manutenção de um suprimento frequente de água para as folhas. A característica morfológica do tronco de $B$. recurvata confere o comportamento isohídrico da espécie (TARDIEU; SIMONNEAU, 1998; MCDOWELL et al., 2008), permitindo que a hidratação das folhas seja contínua em períodos com escassez de água, mesmo quando a porcentagem de água no solo chegue a valores críticos, como observado em nosso estudo. Contudo, deve ser levado em conta que a caracterização do comportamento isohídrico é dependente das condições experimentais, como argumentado por Pou et al. (2012), que constataram que três variedades de videira apresentaram comportamentos distintos aos que foram relatados em estudos anteriores com as mesmas variedades (SCHULTZ, 2003; SOAR et al., 2006; VANDELEUR et al., 2009). Todavia, a característica morfológica dos troncos de plantas paquicaules indica que a isohidria em $B$. recurvata é uma característica evolutiva morfofuncional, independente das condições ambientais.

A análise de fluorescência da clorofila $a$ indicou que os valores de eficiência quântica efetiva do fotossistema II ( $\phi P S I I)$ e coeficiente de extinção fotoquímico $\left(q_{P}\right)$ não foram influenciados pela variação do CRA (Figura 2C e 2D) $(\mathrm{P}>0,05)$, indicando que o período de indução da DL não alterou a eficiência desses parâmetros. Por outro lado, houve uma tendência de decréscimo nos valores da taxa de transporte de elétrons (ETR) e da eficiência quântica potencial do FSII $\left(F_{v} / F_{m}\right)(\mathrm{P}<0,005)$ a medida que o CRA decaiu (Figura 2A e 2B). Paralelamente, o índice de conteúdo de clorofilas total (ICC) reduziu de $31,7 \pm 3,9$ para $14,0 \pm 5,5$ após o período de SI. 


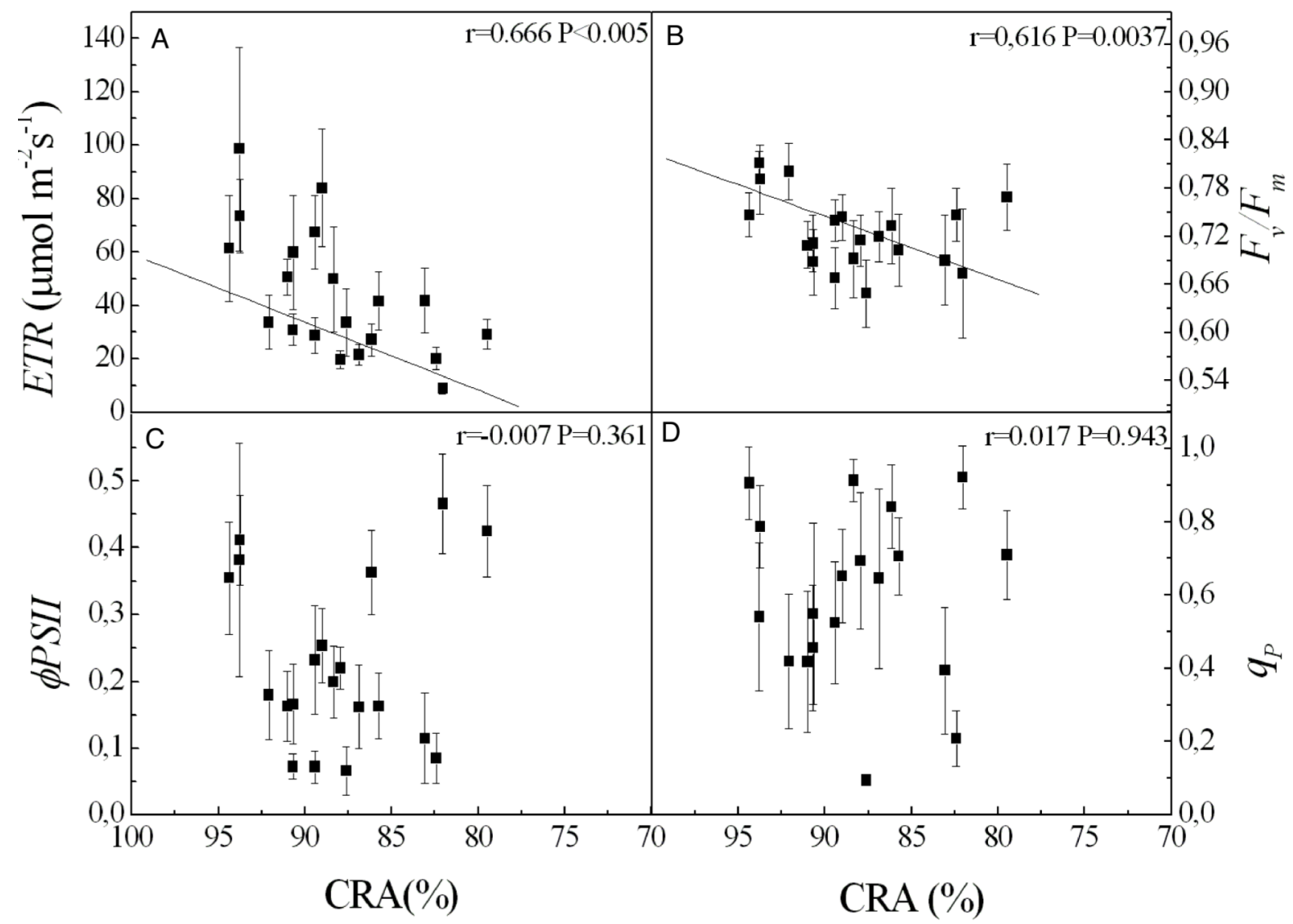

Figura 2. Análise da correlação dos valores de taxa de transporte de elétrons (ETR) (A), eficiência quântica potencial do PSII $\left(F_{v} / F_{m}\right)(\mathrm{B})$, eficiência quântica efetiva do PSII $(\phi P S I I)(\mathrm{C})$ e coeficiente de extinção fotoquímico $q_{P}(\mathrm{D})$, com o conteúdo relativo de água (CRA) em plantas submetidas à indução de desidratação lenta (DL). Os valores foram medidos em dias alternados após a suspensão da irrigação após a suspensão de irrigação. E as médias foram obtidas a partir de seis repetições.

Ao final do período de DL (54 dias) foi observado que a condutância estomática $\left(g_{s}\right)$, a fotossíntese líquida $\left(P_{N}\right)$, a taxa de transporte de elétrons (ETR), a eficiência instantânea de carboxilação (EIC) e a eficiência intrínseca do uso da água (EIUA) foram reduzidas, ao passo que a concentração de carbono intercelular $\left(C_{i}\right)$ aumentou (Figura 3). O decréscimo de $g_{s}, P_{N}$, ETR e EIC foi de aproximadamente $80 \%, 92 \%, 89 \%$ e $97 \%$, respectivamente, enquanto que o $C_{i}$ aumentou 3,5 vezes em comparação com as medidas das plantas hidratadas. Um dia após a reidratação das plantas foi possível observar que a $g_{s}$ e o $P_{N}$ recuperaram totalmente, atingindo valores semelhantes aos medidos no início do experimento. Por outro lado, os valores de ETR e EIC recuperaram parcialmente após a reidratação $(30 \% \mathrm{e}$ $72 \%$, respectivamente), assim como para o $C_{i}$ que manteve os valores acima dos medidos (54\% maior) em comparação as plantas hidratadas. Além disso, no experimento com indução de desidratação rápida (DR), onde as medidas eram realizadas em folhas destacadas das plantas (Figura 4), os resultados indicaram que houve uma alta correlação entre o decréscimo dos valores de $P_{N}$ e $g_{s}(\mathrm{p}<0,0001)$, ou seja, a fotossíntese líquida foi reduzida proporcionalmente à diminuição da condutância estomática. Os valores de
$P_{N}$ atingiram valores nulos após cinco horas de desidratação (Figura 4), indicando que o controle estomático dessa espécie sobre assimilação de carbono é bastante sensível.

Para uma melhor eficiência na manutenção do status hídrico foliar, as espécies isohídricas apresentaram um ajuste estomático mais sensível (MASEDA; FERNÁNDEZ, 2006). Em situação de baixa disponibilidade de água no solo os estômatos se fecham para reduzir a perda de água por transpiração, como pode ser observado para as plantas de $B$. recurvata, que ao final dos 54 dias de DL reduziram de forma expressiva os valores de $g_{s}(80 \%$ em relação às plantas hidratadas) (Figura 3B). A redução da condutância estomática reduz a perda de água pela transpiração, mas também leva a uma redução na entrada de $\mathrm{CO}_{2}$ da atmosfera até o sítio de carboxilação da Rubisco, diminuindo a fotossíntese líquida (CHAVES et al., 2003, 2009; PINHEIRO; CHAVES, 2011).

Por outro lado, apesar dos resultados do experimento com folhas destacadas apontarem uma forte correlação entre a redução estomática e a diminuição da assimilação líquida de $\mathrm{CO}_{2}(\mathrm{r}=0,987 \mathrm{P}<0,0001)$ (Figura 4), indicando alta sensibilidade das trocas gasosas ao controle estomático, os altos valores de $\mathrm{C}_{\mathrm{i}}$ 
após o período prolongado de suspenção da irrigação (Figura 3C) sugerem que a limitação estomática não foi a única causa da redução da fotossíntese. Adicionalmente, a redução dos valores da EIUA (Figura 3D) indica que houve uma redução da eficiência do controle estomático à entrada de $\mathrm{CO}_{2}$, ou seja, a re- dução de $P_{N}$ foi relativamente maior do que a redução de $g_{s}$, suportando a ocorrência de limitação não estomática da fotossíntese. Os altos valores de $\mathrm{C}_{\mathrm{i}} \mathrm{e}$ os baixos valores de $\mathrm{P}_{\mathrm{N}}$ ao final do período de $\mathrm{DL}$ (Figura 3C e A) suportam a hipótese de fatores de limitação não-estomática (BERTOLLI et al., 2012).

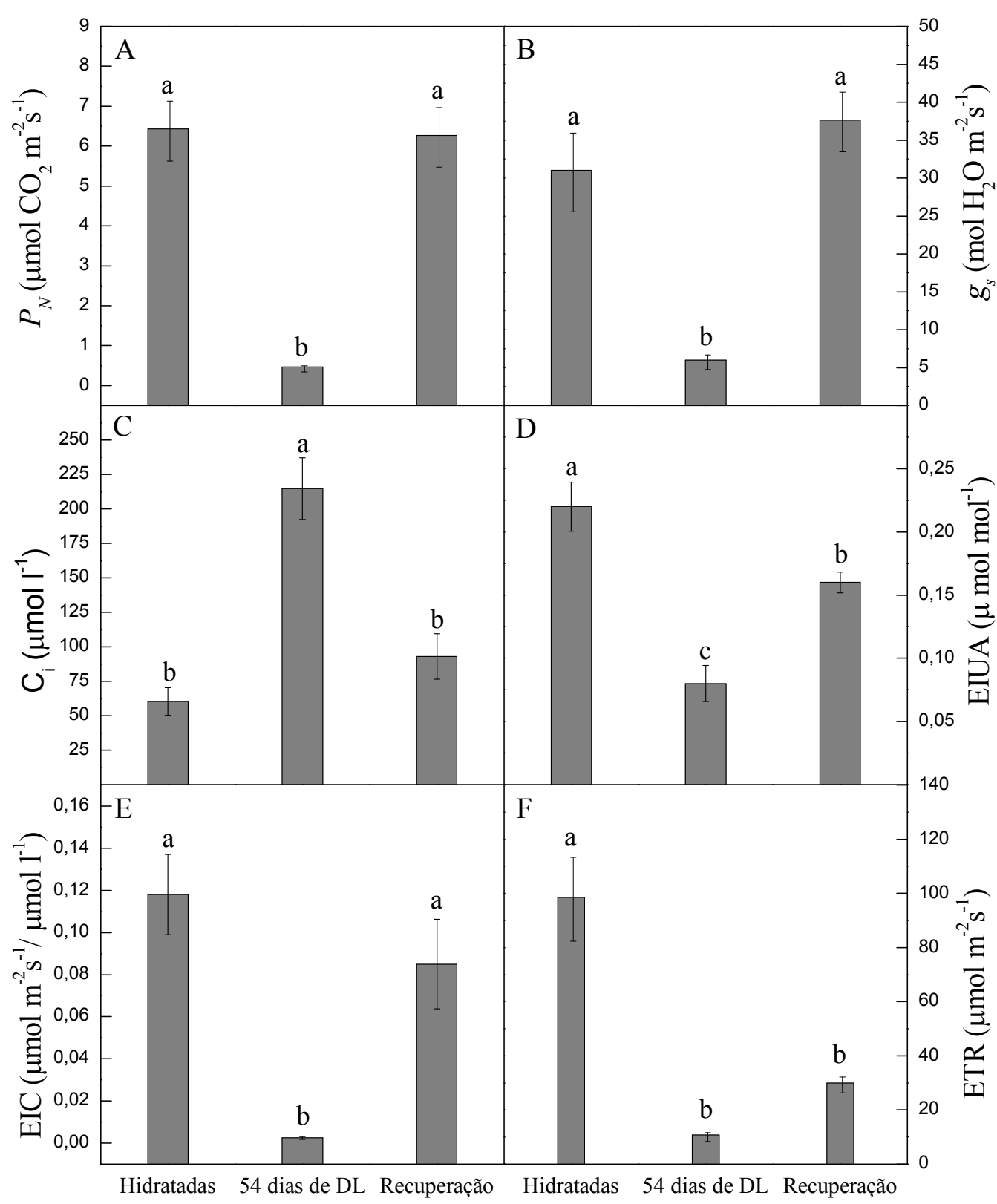

Figura 3. Valores médios e erro padrão de fotossíntese líquida $\left(P_{N}\right)(\mathrm{A})$, condutância estomática $\left(g_{s}\right)(\mathrm{B})$, concentração de carbono intercelular $\left(\mathrm{C}_{\mathrm{i}}\right)(\mathrm{C})$, eficiência intrínseca do uso de água (EIUA) (D), eficiência instantânea de carboxilação (EIC) (E) e taxa de transporte de elétrons (ETR) (F) de plantas irrigadas (Hidratadas) após 54 dias de restrição hídrica (54 dias de DL) e após 24 horas de reidratação (Recuperação). As médias foram obtidas a partir de seis repetições. Letras diferentes indicam diferenças significativas entre os valores médios de cada tratamento $(\mathrm{P}<0,05)$. 


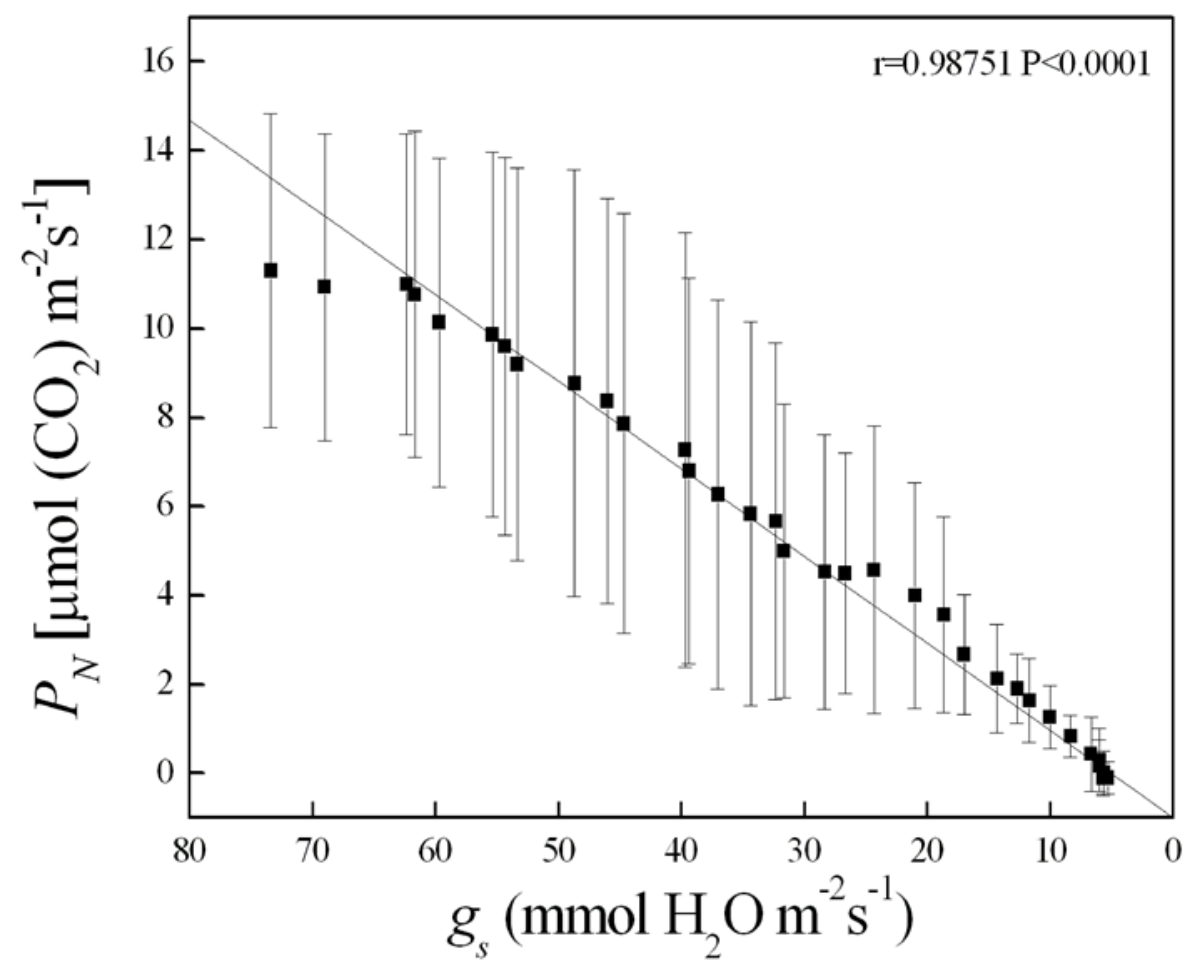

Figura 4. Efeitos da indução de desidratação rápida (DR) na análise de correlação dos valores de condutância estomática $\left(g_{s}\right)$ e fotossíntese líquida $\left(P_{N}\right)$. Média de valores de $\mathrm{g}_{\mathrm{s}}$ e $P_{N}$ medidos a cada 10 minutos após o destacamento das folhas. As médias foram obtidas a partir de oito repetições.

Uma vez que existe uma dependência mútua entre a eficiência da assimilação de $\mathrm{CO}_{2}$ e a eficiência fotoquímica (produção de ATP/NADPH), situações ambientais limitantes podem gerar um desequilíbrio entre a taxa de produção de energia redutora e a taxa de seu consumo pelo ciclo de Calvin, gerando estresse oxidativo (SANDA, 2011). A redução da assimilação de $\mathrm{CO}_{2}$ após 54 dias de suspensão da irrigação pode ter promovido um desequilíbrio entre a fixação bioquímica de $\mathrm{CO}_{2}$ e os elétrons produzidos na etapa fotoquímica. A redução de ETR e $F_{v} / F_{m}$ (Figura $2 \mathrm{~A}$ e $\mathrm{B}$ ) pode ter ocorrido devido a uma menor demanda de energia (ATP/NADPH) requerida para o metabolismo de fixação do carbono, assim como observado por Bertolli et al. (2012). Uma vez a $g_{s}$ ter decaído após o período de DL, a redução da difusão de $\mathrm{CO}_{2}$ da câmara subestomática até o sítio ativo da Rubisco pode ter influenciado a eficiência do ciclo de Calvin, como indicado pela redução dos valores da eficiência instantânea da carboxilação (EIC) (Figura 3E), reduzindo o consumo de ATP/ NADPH, diminuindo a eficiência da cadeia transportadora de elétrons e da eficiência potencial do PSII (Figura 2A e B, respectivamente). Quando o aparato fotoquímico não opera de forma adequada a capacidade de regeneração da ribulose bifosfato (RuBP) diminui, visto que a síntese de ATP e NADPH pode estar comprometida, levando a uma redução na fotossíntese potencial (LAWLOR; TEZARA, 2009; PINHEIRO; CHAVES, 2011).
Os resultados da análise de fluorescência da clorofila $a$ mostraram que a eficiência quântica efetiva $(\phi P S I I)$ e o coeficiente de extinção fotoquímico da fluorescência $\left(q_{P}\right)$ não foram influenciados de forma significativa a medida que os valores de CRA diminuíam (Figura 2C e D). Estudos revelam que o aparato fotoquímico de algumas espécies são resistentes ao estresse hídrico moderado (FLEXAS et al., 2009; BERTOLLI et al., 2014). Portanto, embora a atividade fotoquímica tenha sido reduzida devido ao seu desequilíbrio com a atividade bioquímica da fotossíntese, os resultados de $\phi P S I I$ e $q_{P}$ sugerem uma habilidade da planta em manter uma regulação do aparato fotoquímico apesar das perturbações causadas pela indução da deficiência hídrica.

É necessário levarmos em consideração que embora a $B$. recurvata contenha mecanismos capazes de manter a hidratação dos seus tecidos, possibilitando a manutenção do aparato fotoquímico, o prolongamento do período de DL poderia provocar danos irreversíveis à fotossíntese. Segundo Pou et al. (2012), o comportamento isohídrico não significa sempre uma melhor performance em condições de deficiência hídrica. Isso porque a manutenção das taxas de assimilação de carbono próximas de zero por um período de seca prolongado poderia gerar um acúmulo de energia excedente e, consequentemente, induzir o estresse oxidativo, provocando danos extensivos e irreversíveis ao aparato fotossintético (LAWLOR; CORNIC, 2002). 
Os resultados de recuperação do processo fotossintético, após a reidratação, indicam que não houveram danos irreversíveis ao aparato fotossintético das plantas (Figura 3). A fim de se determinar o nível de severidade do estresse hídrico, Medrano et al. (2002) fazem uso de três intervalos do estado metabólico fotossintético. Quando o estresse hídrico é leve a fotossíntese é limitada somente pela condutância estomática (que reduz a difusão de $\mathrm{CO}_{2}$ ), moderado quando a fotossíntese é reduzida pela condutância do mesofilo e algumas limitações bioquímicas e estresse hídrico severo quando a fotossíntese é limitada principalmente por fatores bioquímicos. Um dia após reidratação das plantas submetidas à deficiência hídrica foi possível notar que a fotossíntese líquida e a condutância estomática de $B$. recurvata recuperaram totalmente os valores medidos antes do início de DL, assim como observado em relação à recuperação dos valores da EIC (Figura 3E). A recuperação da fotossíntese pode ter sido suportada pelo controle estomático mais sensível dessa espécie que preveniu que o aparato fotossintético sofresse danos mais extensivos logo no início da suspensão da irrigação, assim como observado por Bertolli et al. (2012). De acordo com Cornic (2000), um rápido aumento na fotossíntese de plantas reidratadas depois de um período de estresse hídrico indica que o aparato fotoquímico e bioquímico pode não ter sido danificado pela falta de água do solo. Os resultados de recuperação de $P_{N}, g_{s}, \mathrm{C}_{\mathrm{i}}$ e EIC indicam que a deficiência hídrica provocou um estresse apenas moderado nas plantas de $B$. recurvata.

Apesar do estresse hídrico ser considerado moderado neste estudo, a recuperação parcial de ETR sugere que o período de DL (54 dias) foi longo o bastante para reduzir a quantidade de complexos antena, uma vez que houve uma menor quantidade de energia requerida durante a suspensão de irrigação, cuja redução da captação de radiação pode ser necessária a fim de reduzir os danos causados pela sinergia de deficiência hídrica e alta radiação (EPRON et al., 1992). Outro dado que corrobora esta hipótese é a redução de $56 \%$ do teor de clorofila (ICC) de plantas ao final do período de DL, uma vez que o conteúdo de clorofila está relacionado a quantidade de complexos antena. Uma menor quantidade de complexos antena pode indicar uma redução da quantidade de radiação interceptada pelos fotossistemas. Essa resposta sugere um processo de aclimatação dessas plantas a fim de minimizar os efeitos causados por compostos oxidativos produzidos pelo excesso de energia de excitação dos fotossistemas (SILVA; ARRABAÇA, 2004).

\section{CONCLUSÃO}

A $B$. recurvata é uma espécie tolerante à redução da disponibilidade hídrica, mantendo elevado conteúdo relativo de água $(80 \%)$ e apresentando re- cuperação do aparato fotossintético, mesmo após o período prolongado de 54 dias de suspenção de irrigação.

\section{AGRADECIMENTOS}

GM Souza é bolsista produtividade do $\mathrm{CNPq}$ e SC Bertolli é bolsista de doutorado FAPESP (2011/21591-1).

\section{REFERÊNCIAS}

BERTOLLI, S. C.; RAPCHAN, G. L., SOUZA, G. M. Photosynthetic limitations caused by different rates of water-deficit induction in Glycine max and Vigna unguiculata. Photosynthetica. Praha, v. 50, n. 3, p. 329-336, 2012.

BERTOLLI, S. C.; MAZZAFERA, P.; SOUZA, G. $M$. Why is it so difficult to identify a single indicator of water stress in plants? A proposal for a multivariate analysis to assess emergent properties. Plant Biology, Weinheim, v. 16, n. 3, p. 578-585, 2014.

BILGER, W.; BJÖRKMAN, O. Role of the xanthophyll cycle in photoprotection elucidated by measurements of light-induced absorbance changes, fluorescence and photosynthesis in leaves of Hedera canariensis. Photosynthesis Research, Dordrecht, v. 25 , n. 3, p. 173-185, 1990.

BOBICH, E. G.; NORTH, G. B. Structural implication of succulence: Architecture, anatomy, and mechanics of photosynthetic stem succulents, pachycauls, and leaf succulents. In: BARRERA, E.; SMITH, W.K. (Ed.) Perspectives in biophysical plant ecophysiology - A tribute to Park S. Nobel. Universidad Nacional Autonoma de Mexico. Ciudad Universitaria, México, 2009, p. 3-38.

BUCCI, S. J. et al. Water relations and hydraulic architecture in Cerrado trees: adjustments to seasonal changes in water availability and evaporative demand. Brazilian Journal of Plant Physiology, Londrina, v. 20, n. 3, p. 233-245, 2008.

BUCKLEY, T. N. The control of stomata by water balance. New Phytologist, Lancaster, v. 168, n. 2, p. 275-292, 2005.

CHAVES, M. M.; FLEXAS, J.; PINHEIRO, C. Photosynthesis under drought and salt stress: regulation mechanisms from whole plant to cell. Annals of Botany, Exeter, v. 103, n. 4, p. 551-560, 2009.

CHAVES, M. M.; PEREIRA, J. S.; MAROCO, J. Understanding plant response to drought - from 
genes to the whole plant. Functional Plant Biology, Clayton South, v. 30, n. 3, p. 239-264, 2003.

CORNIC, G. Drought stress inhibits photosynthesis by decreasing stomatal aperture - not by affecting ATP synthesis. Trends in Plant Science, London, v. 5, n. 5, p. 183-221, 2000.

EPRON, D.; DREYER, E.; BREDA, N. Photosynthesis of oak tress (Quercus petraea (Matt.) Liebl.) during drought under field conditions: diurnal course of net $\mathrm{CO}_{2}$ assimilation and photochemical efficiency of photosystem II. Plant, Cell \& Environment, Malden, v. 15, n. 7, p. 809-820, 1992.

FLEXAS, J. et al. Photosynthesis limitations during water stress acclimation and recovery in the droughtadapted Vitis hybrid Richter-110 ( $V$. berlandieri $\mathrm{x} V$. rupestris). Journal of Experimental Botany, Lancaster, v. 60, n. 8, p. 2361-2377, 2009.

FLEXAS, J. et al. Keeping a positive carbon balance under adverse conditions: responses of photosynthesis and respiration to water stress. Physiologia Plantarum, Lund, v. 127, n. 3, p. 343-352, 2006.

GIBSON, A. C. The anatomy of succulence. In: TING, I. P.; GIBBS, M. (Ed.) Crassulacean acid metabolism: proceedings of the fifth annual symposium in botany, January 16-16th, commemorating the seventy-fifth anniversary of the Agricultural Experiment Station at the University of California Riverside. American Society of Plant Physiologists, Rockville, Maryland, 1982, p. 1-15.

KRAMER, D. M.; EVANS, J. R. The Importance of Energy Balance in Improving Photosynthetic Productivity. Plant Physiology, Glasgow, v. 155, n. 1, p. 70-78, 2011.

LARCHER, W. Ecofisiologia Vegetal. 1 ed. São Carlos, SP: RiMa, 2000. 531 p.

LAWLOR, D. W.; TEZARA, W. Causes of decreased photosynthetic rate and metabolic capacity in water-deficient leaf cells: a critical evaluation of mechanisms and integration of processes. Annals of Botany, Exeter, v. 103, n. 4, p. 561-579, 2009.

LAWLOR, D. W.; CORNIC, G. Photosynthetic carbon assimilation and associated metabolism in relation to water deficits in higher plants. Plant, Cell \& Environment, Malden, v. 25, n. 2, p. 275-294, 2002.

LORENZI, H.; SOUZA, H. M. Plantas ornamentais no Brasil: arbustivas, herbáceas e trepadeiras. Nova Odessa, SP: Instituto Plantarum, 2008. $988 \mathrm{p}$.

MASEDA, P. H.; FERNÁNDEZ, R. J. Stay wet or else: three ways in wich plants can adjust hydrau- lically to their environment. Journal of Experimental Botany, Lancaster, v. 57, n. 15, p. $3963-$ 3977, 2006.

MCDOWELL, N. et. al Mechanisms of plant survival and mortality during drought: why do some plants survive while others succumb to drought? New Phytologist, Lancaster, v. 178, n. 4, p. 719-739, 2008.

MEDRANO, H. et al. Regulation of photosynthesis of $\mathrm{C} 3$ plants in response to progressive drought: the interest of stomatal conductance as a reference parameter. Annals of Botany, Exeter, v. 89, n. 7, p. 895-905, 2002.

PINHEIRO, C; CHAVES, M. M. Photosynthesis and drought: can we make metabolic connections from avaiable data? Journal of Experimental Botany, Lancaster, v. 62, n. 3, p. 869-882, 2011.

POU, A. et al. Anisohydric behaviour in grapevines results in better performance under moderate water stress and recovery than isohydric behaviour. Plant Soil, Dordrecht, v. 359, n. 1-2, p. 335-349, 2012.

SANDA, S. et al. Responses of the photosynthetic electron transport system to excess light energy caused by water deficit in wild watermelon. Physiologia Plantarum, Lund, v. 142, n. 3, p. 247-264, 2011.

SCHULTZ, H. R. Differences in hydraulic architecture account for near-isohydric and anisohydric behaviour of two fieldgrown Vitis vinifera L. cultivars during drought. Plant, Cell \& Environment, Malden, v. 26, n. 8, p. 1393-1405, 2003.

SILVA, J. M.; ARRABAÇA, M. C. Photosynthesis in the water-stressed $\mathrm{C} 4$ grass Setaria sphacelata is mainly limited by stomata with both rapidly and slowly imposed water deficits. Physiologia Plantarum, Lund, v. 121, n. 3, p. 409-420, 2004.

SOAR, C. J. et al. Gradients in stomatal conductance, xylem sap ABA and bulk leaf ABA along canes of Vitis vinifera cv. Shiraz: biochemical and molecular biological evidence indicating their source. Functional Plant Biology, Clayton South, v. 31, n. 6, p. 659-669, 2004.

SULTAN, S. E. Physiological response to complex environments in annual Polygonum species of contrasting ecological breadth. Oecologia, New York, v. 15 , n. 4, p. 564-578, 1998.

TARDIEU, F.; SIMONNEAU, T. Variability among species of stomatal control under fluctuating soil water status and evaporative demand: modeling isohydric and anisohydric behaviours. Journal of Ex- 
perimental Botany, Lancaster, v. 49, n. (Special issue), p. 419-432, 1998.

VANDELEUR, R. K. et al. The role of plasma membrane intrinsic protein aquaporins in water transport through roots: diurnal and drought stress responses reveal different strategies between isohydric and anisohydric cultivars of grapevine. Plant Physiology, Glasgow, v. 149, n. 1, p. 445-460, 2009.

VON WILLERT, D. J. Life Strategies of Succulents in Deserts. With Special reference to the Namib Desert. 1 ed. New York. Cambridge University Press, 1992. 368 p. 